\title{
Critical Appraisal of Cenobamate as Adjunctive Treatment of Focal Seizures in Adults
}

\author{
Gaetano Zaccara (iD) \\ Simona Lattanzi $\mathbb{( D}^{2}$ \\ Antonio Leo $^{3}$ \\ Emilio Russo (iD ${ }^{3}$ \\ 'Regional Health Agency of Tuscany, \\ Firenze, Italy; ${ }^{2}$ Neurological Clinic, \\ Department of Experimental and Clinical \\ Medicine, Marche Polytechnic University, \\ Ancona, Italy; ${ }^{3}$ Science of Health \\ Department, University Magna Grecia of \\ Catanzaro, Catanzaro, 88100, Italy
}

Correspondence: Gaetano Zaccara Regional Health Agency of Tuscany, via Pietro Dazzi I, Firenze, 50I4I, Italy Tel +39055233685I

Email gaetanozaccara@yahoo.it

\begin{abstract}
Cenobamate (CNB) is the latest antiseizure medication (ASM) authorized for the treatment of focal-onset seizures in adults. Although the precise mechanism of action of CNB is not yet fully understood, this drug inhibits the persistent, rather than transient, voltage-gated sodium channel currents and is a positive allosteric modulator of synaptic and extrasynaptic $\mathrm{GABA}_{\mathrm{A}}$ receptors, differently from benzodiazepines. $\mathrm{CNB}$ has a non-linear pharmacokinetic with a terminal half-life range of about 50/60 hours within the therapeutic dose range, which allows once daily administration. Cenobamate inhibits cytochrome P450 (CYP) 2C19 and induces CYP3A4 and 2B6, and hence can potentially interact with ASMs (eg, phenytoin, carbamazepine and clobazam) and no-ASMs drugs. In two randomized, double-blind, placebo-controlled trials in patients with focal epilepsies, CNB has shown a particularly good efficacy with a rate of seizure freedom of about $20 \%$ during the maintenance period in participants treated with the dose of $400 \mathrm{mg} /$ day. The most common treatment-emergent adverse effects include central nervous systemrelated symptoms, like dizziness, diplopia, somnolence, and gait disturbances. Safety issues of particular interest are severe skin reactions (drug reaction with eosinophilia and systemic symptoms) and QT shortening, which contraindicates its use in subjects with familial short QT syndrome or in combination with other QT-shortening drugs. The recommended starting dose is $12.5 \mathrm{mg} /$ day, which can be gradually titrated to the target dose ( $200 \mathrm{mg} /$ day $)$ and further increased up to $400 \mathrm{mg}$ / day. There are several aspects of CNB that need to be still addressed, including the long-term efficacy and the efficacy in patients with generalized seizures. Ongoing studies will clarify these issues. The clinical relevance of the peculiar pharmacokinetics and the pattern of drug-drug interactions also require further investigation.
\end{abstract}

Keywords: cenobamate, focal seizures, antiseizure medications, drug-drug interactions, safety, efficacy

\section{Key Points}

1. Cenobamate (CNB) is the latest approved antiseizure medication

2. $\mathrm{CNB}$ acts as modulator of voltage-gated sodium channels and $\mathrm{GABA}_{\mathrm{A}}$ currents

3. Adjunctive CNB is very efficacious to reduce seizure frequency in drugresistant patients with focal epilepsy

4. The most common adverse events include somnolence, fatigue, balance disorders, and diplopia

5. Safety issues include severe cutaneous drug reactions and shortened QT interval

\section{Introduction}

Focal epilepsy is the most frequent type of epilepsy. ${ }^{1}$ Focal seizures can be disabling and associated with a low quality of life $^{2}$ and more than one-third of 
patients are not fully controlled despite treatment with single or multiple antiseizure medications (ASMs). ${ }^{3}$ Despite the development and availability of about 30 different drugs, little has changed in the rate of patients who can achieve seizure control and there is still the need of new and more efficacious ASMs. ${ }^{4}$

Cenobamate (CNB) has been approved by the US Food and Drug Administration (FDA) in November 2019 for the treatment of focal seizures in adults and by the European Medicines Agency (EMA) in March 2021 as adjunctive treatment of focal onset seizures with or without secondary generalization. CNB pertains to the class of alkylcarbamates, being, as retigabine and carisbamate, a monocarbamate, and its mechanisms of action are similar to those of other drugs pertaining to this class. ${ }^{5}$

In this review, we will discuss the mechanism of action, pharmacokinetics and drug-drug interactions of $\mathrm{CNB}$ and its efficacy and tolerability in patients with focal seizures.

\section{Mechanism of Action}

The spectrum of efficacy of CNB in animal models indicates that this drug may be effective against seizures, anxiety, and neuropathic pain. ${ }^{6,7}$ Although the precise mechanisms through which CNB exerts these effects are not known yet, experimental evidence suggests that it possesses novel mechanisms of actions affecting both voltage-gated sodium currents (VGSC) and GABAergic neurotransmission. ${ }^{8,9}$

Regarding the effect of VGSCs, studies on acutely isolated hippocampal CA3 neurons demonstrated that CNB reduces repetitive neuronal firing by preferentially inhibiting the non-inactivating portion of sodium currents, also known as $\mathrm{I}_{\mathrm{NaP}}{ }^{8}$, and this mechanism is different from that of several other classical ASMs targeting VGSCs. For example, carbamazepine, lamotrigine and felbamate block use-dependent transient sodium currents $\left(\mathrm{I}_{\mathrm{NaT}}\right)$ that primarily mediate the upstroke of an action potential thus reducing the availability of channels that can generate further action potentials. On the opposite, $\mathrm{I}_{\mathrm{NaP}}$ reduces subthreshold synaptic potentials, thus inhibiting repetitive firing of neurons. This might be a reason for the observed less selective preclinical anti-seizure profile of CNB compared to other ASMs that target $\mathrm{I}_{\mathrm{NaT}} .{ }^{8}$ However, the role of this latter current type deserves to be further investigated to clarify its role in the physiopathology of the central nervous system.
CNB is also able to increase the inhibitory neurotransmission in the brain through a positive allosteric effect on synaptic and extra-synaptic $\mathrm{GABA}_{\mathrm{A}}$ receptors, thus modulating both phasic (Iphasic) and tonic (Itonic) currents. ${ }^{8}$ This mechanism of action is different from the one of benzodiazepines and barbiturates and is more similar to the mechanism of action of stiripentol (a direct allosteric modulator of $\mathrm{GABA}_{\mathrm{A}}$ receptors) ${ }^{9}$ and neurosteroids ${ }^{8}$ that are currently under evaluation as potential ASMs, particularly in the treatment of status epilepticus. ${ }^{9,10,11} \mathrm{CNB}$ affects both phasic and tonic inhibition through activation of synaptic and extra-synaptic $\mathrm{GABA}_{\mathrm{A}}$ receptors. ${ }^{9,10}$ In any case, the binding site for $\mathrm{CNB}$ has not been clarified and could be different from the one of the previously mentioned drugs. ${ }^{8}$

CNB is effective against a variety of animal models of seizures and epilepsy, including models of generalized tonic-clonic seizures, myoclonic seizures, focal seizures, and refractory epilepsy. ${ }^{7}$ Considering the wide spectrum of efficacy in preclinical studies, the chemical structure and similarities with other alkyl-carbamates, it is reasonable to think that the mechanisms of actions of CNB extend beyond what is already known. ${ }^{10}$

\section{Pharmacokinetics}

After oral administration, the absorption of CNB is rapid with a $T_{\max }$ of 1-4 hours; the percentage of absorbed dose is about $88 \%$ and food intake does not cause clinically significant differences in bioavailability. ${ }^{12}$

CNB pharmacokinetic is characterized by some nonlinearity in the process of distribution and/or elimination. While, after single ascending doses, CNB maximum concentration $\left(\mathrm{C}_{\max }\right)$ shows proportional increases, ${ }^{12}$ after multiple doses, the area under the concentration-time curve (AUC) is proportional up to the dose of about $300 \mathrm{mg} /$ day and increases more than proportionally at higher doses. ${ }^{12}$

This nonlinearity regards also terminal half-life that increases, with increasing doses, from 30 hours after a dose of $10 \mathrm{mg}$, up to 76 hours after the highest tested dose of $750 \mathrm{mg}$ and ranges between 50 and 60 hours within the range of therapeutic doses (from $100 \mathrm{mg}$ to $400 \mathrm{mg}$ ). Accordingly, CNB clearance decreases at increasing doses from $1.4 \mathrm{~L} / \mathrm{h}$ to $0.4 \mathrm{~L} / \mathrm{h}$.

The apparent volume of distribution of CNB after oral administration is approximately $40-50 \mathrm{~L}$. This agent has a moderate binding to plasma proteins (mainly human albumin) that is around $60 \%$ and is independent from 
drug concentration. In vitro studies showed that CNB distribution is not influenced by transport proteins such as P-glycoprotein (P-gp), breast cancer-resistance protein (BCRP), organic anion transporter (OAT) $1 / 3$, organic cation transporter (OCT) 2, multidrug and toxin extrusion protein (MATE) 1, and MATE 2-K. ${ }^{13}$

Based on these pharmacokinetic characteristics, steadystate drug concentrations are achieved in approximately 2 weeks of treatment and the drug can be administered oncedaily. ${ }^{13}$

CNB is extensively metabolized in the liver, mainly through glucuronidation via uridine 5'-diphosphoglu curonosyltransferase (UGT) 2B7 and to a lesser extent UGT2B4, and by oxidation via cytochromes P450 (CYP) 2E1, CYP2A6, CYP2B6, and to a lesser extent CYP2C19 and CYP3A4/5 (Table 1). ${ }^{7,13}$

As observed after administration of radiolabelled CNB, only a small percentage of the dose (approximately $6 \%$ ) is excreted unchanged in the urine and eight different inactive metabolites have been identified in plasma, urine, and faeces. ${ }^{13}$

Studies in special populations did not show clinically significant differences in young or elderly subjects or among different sexes or ethnic groups, while it has been observed that drug elimination is affected by hepatic and renal dysfunction. CNB exposure is increased by $2.1-$ to 2.3-fold in mild and moderate hepatic disease, compared with healthy subjects. Renal dysfunction has a lower effect on CNB exposure being 1.4- to 1.5-fold higher in mild or moderate renal impairment. ${ }^{13}$ Due to these changes, lower CNB doses should be administered in subjects with hepatic or renal impairment. Since no studies are available for patients with end-stage renal disease on dialysis or severe hepatic impairment, this drug should not be administered in these patients. ${ }^{13}$

\section{Drug-Drug Interactions}

As previously stated, CNB is metabolized through several UGTs and oxidative CYP enzymes that may be induced or inhibited by several ASMs and NON-ASMs. Therefore, CNB can be victim of several drug-drug interactions (DDIs). However, clinically relevant DDIs are not expected because $\mathrm{CNB}$ is metabolized through multiple enzymatic systems that relatively contribute to CNB metabolism and therefore induction or inhibition of one metabolic pathway usually results in slight changes in the overall drug clearance. ${ }^{13}$

Concerning the effect of CNB on other drugs, in vitro studies showed that CNB inhibits CYP2C19, induces CYP2C8, and may inhibit or induce CYP2B6 and 3A4, while no effects on transporter proteins are expected. ${ }^{12,13}$

\section{Drug-Drug Interactions Between Cenobamate and Other Antiseizure Medications}

DDIs between CNB and old-generation ASMs (carbamazepine, phenytoin, phenobarbital, valproate) have been explored

Table I Main Pharmacokinetics and Metabolism of Cenobamate

\begin{tabular}{|l|l|}
\hline$T_{\max }$ & $\mathrm{I}-4 \mathrm{~h}$ \\
\hline Bioavailability & $88 \%$ \\
\hline $\mathrm{C}_{\max }$ & Dose proportional \\
\hline Terminal half-life & Increases with increasing doses from $30 \mathrm{~h}(10 \mathrm{mg})$ to $76 \mathrm{~h}(750 \mathrm{mg})$. Within therapeutic ranges of doses, half-life is $50-60 \mathrm{~h}$. \\
\hline Pharmacokinetics & Non-linear. Area under the curve increases more than proportionally with ascending doses \\
\hline $\mathrm{V}_{\mathrm{d}}$ & $40-50 \mathrm{~L}$ \\
\hline Protein binding & $60 \%$ \\
\hline Metabolism & $\begin{array}{l}\text { Glucuronidation: UGT2B7 and to a minor extent UGT2B4. } \\
\text { Oxidation: CYP2EI, 2A6, 2B6, and to a lesser extent 2C19 and 3A4/5. }\end{array}$ \\
\hline Elimination & $\begin{array}{l}6 \% \text { of dose excreted in the urine as unchanged drug. } \\
\text { Biliary } 5 \%(<1 \% \text { unchanged). } \\
8 \text { Inactive metabolites identified. }\end{array}$ \\
\hline
\end{tabular}

Notes: Data from cenobamate highlights of prescribing information (https://www.accessdata.fda.gov/drugsatfda_docs/label/2019/2/2839s000|bl.pdf), ${ }^{13}$ Vernillett et al ${ }^{12}$ and Roberti et al. ${ }^{7}$

Abbreviations: $C_{\max }$, Maximum concentration; CYP, cytochrome P450; $T_{\max }$, time to maximum concentration; UGT, uridine 5'-diphospho-glucuronosyltransferase; $V_{d}$, volume of distribution. 
in healthy volunteers in Phase I studies (results of these studies have not been extensively published). ${ }^{15}$ Concomitant administration of $\mathrm{CNB}$ with phenytoin and phenobarbital was associated with a mild reduction of the AUC of CNB, while CNB exerted a strong inhibition of metabolism of phenytoin and phenobarbital increasing their levels by $84 \%$ and $37 \%$, respectively. These DDIs have been confirmed in an openlabel clinical study in which, during CNB titration, patients required dose reductions of phenytoin and phenobarbital by $43.4 \%$ and $29.7 \%$ respectively. ${ }^{16}$ These effects are the consequence of the inhibition of the enzyme CYP2C19, involved in the metabolism of the two old-generation ASMs. Carbamazepine levels were instead moderately reduced because of the inducing effects of CNB on CYP3A4. ${ }^{12,14,16}$

The induction of CYP3A4 and inhibition of CYP2C19 exerted by CNB may potentially alter concentrations of several other ASMs. The induction of CYP3A4 may increase the metabolism and consequently reduce levels of those old- and new-generation ASMs that are mainly or partially metabolized by this enzyme, such as ethosuximide, clonazepam, felbamate, midazolam, perampanel and zonisamide. ${ }^{17}$ It has also been reported that lamotrigine and levetiracetam concentrations can be mildly reduced by CNB administration through unspecified mechanisms. ${ }^{7,13}$

The inhibition of CYP2C19 may reduce the metabolism of ASMs metabolized by this enzyme, such as brivaracetam, cannabidiol and desmethylclobazam (the active metabolite of clobazam) with the consequence of increasing their plasma concentrations. ${ }^{7,13}$

Based on these data, therapeutic drug and clinical monitoring with possible change in the dose of the ASMs to whom CNB is added should be considered at the beginning and throughout treatment. The DDIs exerted by CNB on other ASMs are summarized in Table 2.

\section{Drug-Drug Interactions Between Cenobamate and Other Drugs}

CNB may potentially interact with other drugs concomitantly administered for treatment of comorbidities or other disorders. It can be predicted that $\mathrm{CNB}$ acts as the perpetrator in most cases, but it cannot be excluded that in some cases CNB can be also the victim of a DDI, although, in this last case, interactions would likely not be clinically relevant. A selection of the most important potential DDIs according to the CYPs involved in the metabolism of drugs is reported in Table 3. In some cases, the metabolism of a co-administered drug might be induced or inhibited with yet uncertain results.

\section{Cenobamate Efficacy from Regulatory Trials}

Two multi-center, parallel-group, randomized, placebocontrolled trials have evaluated the clinical efficacy of CNB in patients with drug-resistant focal epilepsies. ${ }^{18,19}$ Both studies had an 8-week observational baseline and a 6-week titration period; the maintenance period was 6 weeks in one study ${ }^{18}$ and 12 weeks in the other trial. ${ }^{19}$ Patients were randomized to placebo or CNB at the dose of $200 \mathrm{mg} /$ daily in the first study ${ }^{18}$; the second trial was a four arms study, ${ }^{19}$ being patients randomized to placebo or CNB at the daily dosage of $100 \mathrm{mg}, 200 \mathrm{mg}$, or $400 \mathrm{mg}$. In both studies, patients already being treated with up to three ASMs were allowed to enter, and the most frequently used ASMs were levetiracetam, followed by carbamazepine, lamotrigine and oxcarbazepine. No patient was under treatment with phenobarbital, phenytoin, brivaracetam and cannabidiol whose metabolism could be inhibited by CNB, while in one study, a percentage of $5 \%$ to $16 \%$ of the patients were treated with clobazam (whose active metabolite, desmethylclobazam, can be inhibited by CNB). ${ }^{19}$ For this reason, it was not likely that results could be influenced by increased concentrations and efficacy of the combined ASMs. The main findings of these studies are reported in Table 4.

Efficacy and tolerability of CNB from these studies have been assessed in a classical meta-analysis: ${ }^{20}$ the risk ratio of the outcome measure "fifty percent or greater reduction in baseline seizure frequency during the treatment maintenance period" resulted significantly different when all doses were pooled and for each of the used doses $(100 \mathrm{mg} / \mathrm{day}, 200 \mathrm{mg} /$ day, and $400 \mathrm{mg}$ /day). In addition, when given at the daily dosage of 200 and $400 \mathrm{mg}$, CNB was significantly more effective than placebo in reducing baseline seizure frequency by $>75 \%$ and by $>90 \%$. Seizure freedom during the treatment maintenance period was also more frequently reported in patients randomized to CNB at the daily dosages of $200 \mathrm{mg}$ and $400 \mathrm{mg}$ than placebo (Table 5).

Results emerging from these two trials ${ }^{18,19}$ suggest a very high efficacy of CNB compared to all other ASMs recently entered the market. In particular, while seizure free rates of patients recruited in pivotal trials of the last new ASMs evaluating perampanel ${ }^{21}$ and brivaracetam ${ }^{22}$ ranged from $0 \%$ to $6.5 \%$, about $14 \%$ of the patients treated with CNB at the dose of $400 \mathrm{mg} /$ day achieved this outcome in the largest study. ${ }^{19}$ It may be interesting to note that recent observational studies showed that the seizure free rate of patients that failed 
Table 2 Effects of Cenobamate on Drug Levels of Antiseizure Medications

\begin{tabular}{|c|c|c|c|}
\hline & Antiseizure Medications & $\begin{array}{l}\text { Mechanism of the } \\
\text { Interaction }\end{array}$ & Clinical Considerations \\
\hline \multirow[t]{2}{*}{$\begin{array}{l}\text { Drugs whose metabolism can be } \\
\text { increased }\end{array}$} & $\begin{array}{l}\text { Carbamazepine } \\
\text { Clonazepam } \\
\text { Ethosuximide } \\
\text { Felbamate } \\
\text { Midazolam } \\
\text { Perampanel } \\
\text { Zonisamide }\end{array}$ & CYP3A4 induction & Consider to increase dose* \\
\hline & $\begin{array}{l}\text { Lamotrigine } \\
\text { Levetiracetam }\end{array}$ & Unspecified mechanism & Consider to increase dose* \\
\hline $\begin{array}{l}\text { Drugs whose metabolism can be } \\
\text { decreased }\end{array}$ & $\begin{array}{l}\text { Brivaracetam } \\
\text { Desmethylclobazam (active } \\
\text { metabolite of clobazam) } \\
\text { Phenytoin } \\
\text { Phenobarbital } \\
\text { Primidone }\end{array}$ & CYP2C9 inhibition & Consider to reduce dose* \\
\hline $\begin{array}{l}\text { Drugs whose metabolism can be either } \\
\text { increased or decreased }\end{array}$ & $\begin{array}{l}\text { Cannabidiol } \\
\text { Stiripentol }\end{array}$ & $\begin{array}{l}\text { CYP2CI9 inhibition and } \\
\text { CYP3A4 induction }\end{array}$ & $\begin{array}{l}\text { Either an increase or a decrease of } \\
\text { dose should be considered* }\end{array}$ \\
\hline $\begin{array}{l}\text { Drugs whose metabolism should not } \\
\text { be influenced }\end{array}$ & $\begin{array}{l}\text { Eslicarbazepine acetate } \\
\text { Gabapentin } \\
\text { Oxcarbazepine } \\
\text { Lacosamide } \\
\text { Pregabalin } \\
\text { Rufinamide } \\
\text { Topiramate } \\
\text { Valproate } \\
\text { Vigabatrin }\end{array}$ & & No action required \\
\hline
\end{tabular}

Notes: $*$ The effect may be clinically important or of low clinical relevance. Data from Vernillett et al, ${ }^{15}$ Roberti et al ${ }^{7}$ and cenobamate highlights of prescribing information (https://www.accessdata.fda.gov/drugsatfda_docs/label/2019/212839s000lbl.pdf). ${ }^{13}$

Abbreviation: CYP, cytochrome P450.

Table 3 Drugs Whose Metabolism is Potentially Affected by Cenobamate

\begin{tabular}{|l|l|l|}
\hline $\begin{array}{l}\text { Cytochrome } \\
\text { Involved in the } \\
\text { Interaction }\end{array}$ & $\begin{array}{c}\text { Selection of Drugs Whose Metabolism Can } \\
\text { Be Affected }\end{array}$ & Mechanism of the Interaction and Clinical Considerations \\
\hline CYP3A4 substrates & $\begin{array}{l}\text { Ifosfamide, itraconazole, ketamine, methadone, } \\
\text { nevirapine, omeprazole, sorafenib, tamoxifen, } \\
\text { ticlopidine. } \\
\text { Oral contraceptives* }\end{array}$ & $\begin{array}{l}\text { Due to the inducing effects of CNB on this enzyme, reduction of the } \\
\text { concentrations of these drugs are expected. Consider to increase the } \\
\text { dose of the co-administered drug }\end{array}$ \\
\cline { 1 - 2 } CYP2B6 substrates & Bupropion, ketamine, propofol, selegiline & $\begin{array}{l}\text { Due to the inhibiting effects of CNB on this enzyme, an increase of } \\
\text { the concentrations of these drugs are expected. Consider to decrease } \\
\text { the dose of the co-administered drug }\end{array}$ \\
\hline CYP2C19 substrates & \begin{tabular}{l} 
Ifosfamide, omeprazole, sertraline \\
\hline
\end{tabular} &
\end{tabular}

Notes: *An alternative type of birth control should be recommended. Data from Roberti et al. ${ }^{7}$

Abbreviations: CNB, cenobamate; CYP, cytochrome P450. 
Table 4 Main Results on Efficacy and Tolerability of Clinical Studies on Cenobamate

\begin{tabular}{|c|c|c|c|c|c|}
\hline Study & Treatment Arm & $\begin{array}{l}\text { Responder } \\
\text { Rate, \% }\end{array}$ & $\begin{array}{l}\text { Median Percentage Reduction } \\
\text { in Baseline Seizure Frequency }\end{array}$ & $\begin{array}{c}\text { Seizure } \\
\text { Freedom } \\
\text { Rate, \% }\end{array}$ & $\begin{array}{l}\text { Treatment Withdrawal Rate } \\
\text { Due to Adverse Events, \% }\end{array}$ \\
\hline $\begin{array}{l}\text { Chung et al } \\
2020^{18}\end{array}$ & $\begin{array}{c}\text { Placebo } \\
\text { CNB } 200 \mathrm{mg} / \text { day }\end{array}$ & $\begin{array}{l}22.2(108)^{\circ} \\
50.4(113)^{\circ}\end{array}$ & $\begin{array}{l}21.5(108)^{\circ} \\
55.6(113)^{\circ}\end{array}$ & $\begin{array}{l}9.1(99)^{\circ} \\
27.5(102)^{\circ}\end{array}$ & $\begin{array}{l}3.7(108)^{\circ} \\
3.5(113)^{\circ}\end{array}$ \\
\hline $\begin{array}{l}\text { Krauss et al } \\
2020^{19}\end{array}$ & $\begin{array}{c}\text { Placebo } \\
\text { CNB } 100 \mathrm{mg} / \text { day } \\
\text { CNB } 200 \mathrm{mg} / \text { day } \\
\text { CNB } 400 \mathrm{mg} / \text { day }\end{array}$ & $\begin{array}{l}25(102)^{\circ 00} \\
40(102)^{\circ 00} \\
56(98)^{\circ 00} \\
64(95)^{\circ 00}\end{array}$ & $\begin{array}{l}27(102)^{\circ 00} \\
41.5(102)^{\circ 00} \\
56.5(98)^{\circ 00} \\
63.0(95)^{\circ 00}\end{array}$ & $\begin{array}{l}1(106)^{\circ 0} \\
3(108)^{\circ} \\
9(109)^{\circ 0} \\
14(111)^{\circ}\end{array}$ & $\begin{array}{l}5(108)^{\circ} \\
11(108)^{\circ} \\
14(110)^{\circ} \\
21(111)^{\circ}\end{array}$ \\
\hline
\end{tabular}

Notes: Data from Chung et al ${ }^{18}$ and from Krauss et al. ${ }^{19}$ Percentages are calculated on different populations of patients as reported in parentheses. Intention-to-treat population (ITT). ${ }^{\circ}$ Completer population during the maintenance phase. ${ }^{\circ 0}$ Modified intention-to-treat population during the maintenance phase. A responder is defined as a subject with a $\geq 50 \%$ reduction in baseline seizure frequency.

Abbreviation: CNB, cenobamate.

Table 5 Main Results of a Meta-Analysis of the Two Randomized, Placebo-Controlled Studies on Adjunctive Cenobamate

\begin{tabular}{|l|c|c|c|c|}
\hline \multirow{2}{*}{ Dose Administered } & \multicolumn{2}{|c|}{ Responder Rate } & \multicolumn{2}{c|}{ Seizure Freedom } \\
\cline { 2 - 5 } & Risk Ratio & 95\% Confidence Interval & Risk Ratio & 95\% Confidence Interval \\
\hline $100 \mathrm{mg} /$ day & 1.58 & $1.05-2.37$ & 4.00 & $0.45-35.18$ \\
$200 \mathrm{mg} /$ day & 2.25 & $1.71-2.98$ & 3.66 & $1.90-7.06$ \\
$400 \mathrm{mg} /$ day & 2.52 & $1.75-3.63$ & 21.47 & $2.94-156.91$ \\
All doses pooled & 2.18 & $1.67-2.85$ & 3.71 & $1.93-7.14$ \\
\hline
\end{tabular}

Notes: Data from Lattanzi et al $2020 .{ }^{20}$ Risk ratio of the outcome measures "fifty percent or greater reduction in baseline seizure frequency during the treatment maintenance period (responder rate)" and number of patients seizure free during the maintenance period.

to respond to the first ASM exponentially decays with the number of drug trials. ${ }^{3,23}$ For example, the percentage of seizure free patients is about $4.4 \%$ after the third ASM regimen. ${ }^{24}$ Since the time elapsed from diagnosis to randomization in patients recruited in the CNB clinical studies was around 20 years, ${ }^{18,19}$ it can be hypothesized that a great number of patients had several unsuccessful drug trials before entering the trials and this enhances further the good efficacy profile of CNB. Long-term studies will clarify how seizures can be fully controlled by CNB over time. At this moment, only a small long-term study (up to 8 years) reporting efficacy data of 49 patients with severe drug resistant focal epilepsies who had participated in the early CNB clinical development has been published, and 16 (33\%) patients had their seizures controlled for at least 6 months. ${ }^{25}$ It should be stressed that seizure freedom is a target of critical importance and a major determinant of good quality life. ${ }^{2}$

Concerning seizure type, the frequency of both focal motor seizures, with or without impaired awareness, and secondarily generalized tonic-clonic seizures was significantly reduced, and the effect was greater at the $200 \mathrm{mg}$ and $400 \mathrm{mg}$ CNB dose groups.

\section{Safety and Tolerability}

Data on safety and tolerability of CNB are derived from randomized controlled trials ${ }^{18,19,26}$ and from an interim analysis of an open-label long-term study that was conducted to assess the safety and clinical impact of drug interactions on tolerability. ${ }^{16}$

The most frequent adverse effects significantly associated with CNB include typical neurological symptoms commonly observed during treatment with ASMs and more specifically with sodium channel blockers. Reported symptoms include somnolence, fatigue, dizziness, balance disorder, diplopia, nystagmus. Nausea and vomiting, possibly correlated with the effect of this agent on vestibulocerebellar function, and constipation were also frequently observed. In general, these adverse effects were observed at the beginning of therapy and tended to abate over the time. Their frequency was probably influenced by the high starting dose (100 mg/day), rapid titration schedule (weekly increments of $100 \mathrm{mg} /$ day) ${ }^{18}$ and co-administered ASMs. Notably, in randomized clinical studies, baseline treatments could not have their doses reduced or withdrawn during the double-blind phase as per study protocol. ${ }^{18,19}$ 
In the open-label, long-term, study aimed to assess idiosyncratic adverse effects and DDIs ${ }^{16}$ of $\mathrm{CNB}$, initial daily dose of this agent was $12.5 \mathrm{mg}$ and dose increments were of $12.5 \mathrm{mg} /$ day after the first 2 weeks and then $50 \mathrm{mg} /$ day every 2 weeks. Concerning possible changes in baseline treatments, two different approaches were allowed. While most concomitant ASMs could have their dose adjusted or could be removed as clinically needed, in the case of phenytoin and phenobarbital, whose metabolism is inhibited by $\mathrm{CNB}$, changes were possible only under guidance of plasma levels of these drugs. Treatment-emergent adverse effects that led to study discontinuation occurred mainly during the titration period and involved central nervous system (Table 6). Most frequent neurologic, dose-dependent adverse effects were somnolence, dizziness, fatigue, diplopia and balance disorder. Rash was reported in $3.3 \%$ of the patients. Psychiatric adverse events were unfrequently reported and included anxiety, irritability, and depression. Three subjects, two of whom had a history of depression, made a suicide attempt.

Finally, cognitive disturbances (memory impairment, disturbance in attention, amnesia, confusional state, aphasia, speech disorder, slowness of thought, disorientation, and psychomotor retardation) have also been reported in clinical studies. ${ }^{13}$

There are four warnings reported in the FDA highlights of prescribing information. ${ }^{13}$

1. Neurological adverse effects. These reactions (already discussed) require attention for their possible consequences (eg, fall, attention disturbances during driving).

2. Drug Reaction with Eosinophilia and Systemic Symptoms (DRESS). In early studies in which CNB had been titrated rapidly, three cases of DRESS, formerly known as multi-organ hypersensitivity, including one fatality, have been reported. ${ }^{13}$ This is a serious and potentially life-threatening immune-mediated, drug reaction rarely observed in patients exposed to aromatic ASMs, mainly carbamazepine, phenytoin, and lamotrigine. ${ }^{27}$ Since that observation, one further case has been described: it occurred after 24 days of treatment in a patient assigned to receive $200 \mathrm{mg}$ /day of CNB with a fast titration protocol in the Phase 3 study. ${ }^{18}$ However, in the open-label study that adopted a lower starting dose $(12.5 \mathrm{mg} /$ day $)$ and a slower titration (increments every 2 weeks), ${ }^{16}$ no further cases of DRESS were observed among 1339 patients exposed to CNB for a median of 9 months. It can be suggested that, as for other ASMs such as lamotrigine, ${ }^{27}$ a low initial dose and a slow titration can greatly reduce the risk of this serious complication.

3. Effects on cardiac repolarization. Several drugs may affect QT interval, that is the time required for ventricular depolarization and repolarization of the heart to occur. Changes in the QT interval are associated with an increased risk of fatal arrhythmias. ${ }^{28,29}$ For this reason, from 2005, formal studies (placebo and active drug-controlled studies conducted in healthy volunteers) are required to evaluate the effect of therapeutic and supratherapeutic doses of any new agent on ECG during clinical drug development. ${ }^{30}$ Several ASMs, mainly those that target sodium channels, may alter cardiac repolarization. ${ }^{31}$ In the CNB formal study, it has been found that this agent shortens QT interval of more than 20 msec compared with placebo in $31 \%$ of the subjects at the dose of $200 \mathrm{mg}$ and in $66 \%$ of the subjects at the dose of $500 \mathrm{mg} .{ }^{13}$ Consequently, $\mathrm{CNB}$ is not recommended in patients with familial short QT syndrome and should be used with caution when combined with other drugs that shorten QT interval such as primidone or rufinamide. ${ }^{13}$

4. Risk of suicide attempts. There is a suspect that all ASMs, as a class and across all ranges of indications, may be associated with a small increment of suicidal thoughts or behaviour $^{32}$ even though a more recent analysis failed to confirm this finding. ${ }^{33}$ In the open-label CNB study, ${ }^{16}$ three cases of suicide attempt and one case of serious suicidal ideation have been reported. Although a clear association between this drug and suicide has not been demonstrated, FDA recommends monitoring for suicidal behaviour and ideation patients treated with $\mathrm{CNB}$, as recommended for several other ASMs. ${ }^{13}$

\section{Discussion}

CNB is the most recently approved ASM and its profile is particularly interesting under several points of view. There are several critical questions that deserve a comment.

The efficacy profile of CNB that emerges from two relatively small randomized clinical studies should be 
Table 6 Most Important and/or Frequent Adverse Events Observed During Cenobamate Treatment in Double-Blind Trials and OpenLabel Long-Term Study

\begin{tabular}{|l|c|c|}
\hline & $\begin{array}{l}\text { Patients Treated with CBN in Double-Blind } \\
\text { Studies with the Adverse Event, \% }\end{array}$ & $\begin{array}{l}\text { Patients in the Open-Label Long-Term Study } \\
\text { with the Adverse Event, \% }\end{array}$ \\
\hline $\begin{array}{l}\text { Adverse events leading to } \\
\text { drug discontinuation }\end{array}$ & 11.0 & 12.2 \\
\hline Central nervous system & & 28.1 \\
Somnolence & 24.7 & 16.6 \\
Fatigue & 16.1 & 23.6 \\
Dizziness & 23.3 & 5.5 \\
Balance disorder & 5.4 & $\mathrm{NR}$ \\
Nystagmus & 5.7 & 5.8 \\
Diplopia & 10.9 & 6.0 \\
\hline Gastrointestinal system & & $\mathrm{NR}$ \\
Nausea & 7.0 & \\
Vomiting & 3.8 & \\
\hline
\end{tabular}

Note: Data from Lattanzi et al ${ }^{20}$ and Sperling et al. ${ }^{16}$

Abbreviation: NR, not reported.

confirmed in the long term. Up to now, open-label, longterm studies on patients recruited in the pivotal randomized clinical studies have not been published yet, and open-label naturalistic studies similar to those available for other third-generation $\mathrm{ASMs}^{34-38}$ are still not available. Hence, we do not know how many drug-resistant patients with focal epilepsies that achieved seizure freedom over few months in the randomized, double-blind studies will keep on without seizures over the years. In addition, a precise comparative direct and/or indirect assessment with other ASMs seems of particular importance. Will CNB result more effective than the other ASMs that have been recently introduced in the market? Under this aspect, comparative analyses on efficacy with other ASMs should consider the high placebo response observed in CNB registrative studies. It should be considered that placebo response in double-blind studies of ASMs has increased over the years for reasons that are not jet clearly understood. $^{39,40}$

A further consideration regards the dual mechanism of action of $\mathrm{CNB}$ both on the non-inactivating portion of VGSCs and the phasic and tonic inhibitory currents of synaptic and extrasynaptic $\mathrm{GABA}_{\mathrm{A}}$ receptors. It seems reasonable to hypothesize that the high efficacy profile of this drug is the consequence of such novel mechanisms of action. A critical point that should be studied in the future is whether there are pharmacodynamic interactions between $\mathrm{CNB}$ and other ASMs. Will the CNB efficacy profile be influenced by concomitant ASMs, particularly those affecting VGSC with different mechanisms or those affecting GABAergic transmission? In other words, will CNB have super-additive, additive or infra-additive pharmacodynamic interactions concerning efficacy or tolerability with other ASMs ${ }^{41}$ It is known that concomitant use of agents blocking VGSC is associated with low increase in efficacy and higher incidence of neurological adverse effects. ${ }^{42,43}$

A third critical point is the evaluation of the spectrum of efficacy of CNB. Will this agent be effective on other type of seizures? Interestingly, studies on animal models suggest a broader anti-seizure profile of CNB compared to other VGSC blockers, and for this reason, it has been hypothesized that CNB might have other, still unknown, mechanisms of action. ${ }^{7,8}$ In a single-blind study, it has been demonstrated that a single CNB dose is effective in suppressing generalised paroxysmal discharges in subjects with photosensitive epilepsy and that this effect increases with increasing doses, ${ }^{44}$ thus suggesting the efficacy on generalized epilepsies. Two studies in patients with primary generalized tonic-clonic seizures are ongoing and, hopefully, will answer this question in the near future. ${ }^{45}$

The fourth point is how certain pharmacokinetic characteristics, DDIs and some potential adverse effects of CNB will impact the management of patients with epilepsy in the real-world and whether these will limit the use of this drug. For example, the low starting dose and slow titration that are needed to reduce the risk of serious idiosyncratic drug reactions and avoid dose-dependent neurologic adverse effects, 
may limit the use of CNB when a rapid onset of action is required. For the treatment of patients with status epilepticus, episodes of cluster seizures and acute repetitive seizures, a drug that needs to be started at a sub-therapeutic dose and slowly titrated does not look the preferable choice. In addition, $\mathrm{CNB}$ non-linear kinetics may cause more than proportional drug concentrations at high doses with consequent possible intolerable neurological adverse effects. It needs to be clarified whether, as it happens for phenytoin, ${ }^{46}$ monitoring of blood levels of $\mathrm{CNB}$ may be important to individualize the optimal drug dose, particularly in patients treated with high doses.

Surely, plasma levels of some concomitant ASMs should be monitored. For example, plasma levels of the old-generation ASMs phenytoin and phenobarbital (metabolised by CYP2C19) and carbamazepine (metabolised by CYP3A4) should be monitored, at the beginning of CNB treatment, because of the inhibitory or inducing effects of CNB on these enzymes. Similarly, clobazam and its active metabolite may be linked to somnolence development and dosages adjusted and monitored.

\section{Conclusion}

The use of this new agent in clinical practice will require knowledge and careful clinical observation by skilled epileptologists and neurologists. It is recommended to start CNB with a low dose $(12.5 \mathrm{mg} /$ day $)$ that must be titrated gradually to the target dose of $200 \mathrm{mg} /$ day. This dose may be increased to a maximum of $400 \mathrm{mg} /$ day, whether clinically needed. Due to possible interactions, doses of concomitant ASMs may require adjustment. The stepwise tapering off of a previously ineffective drug may be attempted to increase tolerability and reduce the risk of treatment failure due to side effects. In addition, efficacy and tolerability of other drugs administered for the treatment of possible comorbid diseases may require dose adjustments. With all these caveats, there is hope that several drug-resistant patients will benefit from this treatment. Ongoing clinical studies will confirm and expand the efficacy spectrum of CNB in epilepsy patients.

\section{Acknowledgments}

The Italian Medicines Agency (AIFA) and Regione Calabria are kindly acknowledged for their financial support of the pharmacovigilance project AIFA 2012-2014 entitled "Studio regionale di farmacovigilanza attiva per valutazione di sicurezza, appropriatezza prescrittiva, efficacia ed aderenza alla terapia con i nuovi antiepilettici”. These funders had no active role in the data collection and analysis, decision to publish or preparation of this manuscript.

\section{Disclosure}

Gaetano Zaccara has received speaker's or consultancy fees from Eisai, UCB Pharma and Jazz Pharmaceuticals, and has served on the advisory board for GW Pharmaceuticals. Simona Lattanzi has received speaker's or consultancy fees from Angelini Pharma, Eisai, GW Pharmaceuticals, and UCB Pharma and has served on advisory boards for Angelini Pharma, Arvelle Therapeutics, BIAL, and GW Pharmaceuticals. Antonio Leo has no conflicts of interest for this work. Emilio Russo has received speaker fees, grants or funding from, and has participated in advisory boards for Angelini, Arvelle Therapeutics, Eisai, Pfizer, GW Pharmaceuticals, UCB, Kolfarma, and Lundbeck. The authors report no other potential conflicts of interest for this work.

\section{References}

1. Beghi E. The epidemiology of epilepsy. Neuroepidemiology. 2020;54:185-191. doi:10.1159/000503831

2. Josephson CB, Patten SB, Bulloch A, et al. The impact of seizures on epilepsy outcomes: a national, community-based survey. Epilepsia. 2017;58:764-771. doi:10.1111/epi.13723

3. Kwan P, Brodie MJ. Early identification of refractory epilepsy. $N \quad$ Engl $J$ Med. 2000;342:314-319. doi:10.1056/NEJM20 0002033420503

4. French JA, White HS, Klitgaard H, et al. Development of new treatment approaches for epilepsy: unmet needs and opportunities. Epilepsia. 2013;54:3-12. doi:10.1111/epi.12294

5. Löscher W, Sills GJ, White HS. The ups and downs of alkyl-carbamates in epilepsy therapy: how does cenobamate differ? Epilepsia. 2021;62(3):596-614. doi:10.1111/epi.16832

6. Guignet M, Campbell A, White HS. Cenobamate (XCOPRI): can preclinical and clinical evidence provide insight into its mechanism of action? Epilepsia. 2020;61:2329-2339. doi:10.1111/epi.16718

7. Roberti R, De Caro C, Iannone LF, Zaccara G, Lattanzi S, Russo E. Pharmacology of cenobamate: mechanism of action, pharmacokinetics, drug-drug interactions and tolerability. CNS Drugs. 2021;35 (6):609-618. doi:10.1007/s40263-021-00819-8

8. Nakamura M, Cho JH, Shin HS, Jang IS. Effects of cenobamate (YKP3089), a newly developed anti-epileptic drug, on voltage-gated sodium channels in rat hippocampal CA3 neurons. Eur J Pharmacol. 2019;855:175-182. doi:10.1016/j.ejphar.2019.05.007

9. Fisher JL. The effects of stiripentol on GABA(A) receptors. Epilepsia. 2011;52:76-78. doi:10.1111/j.1528-1167.2011.03008.x

10. Sharma R, Nakamura M, Neupane C, et al. Positive allosteric modulation of GABAA receptors by a novel antiepileptic drug cenobamate. Eur J Pharmacol. 2020;879:173117. doi:10.1016/j. ejphar.2020.173117

11. Lattanzi S, Riva A, Striano P. Ganaxolone treatment for epilepsy patients: from pharmacology to place in therapy. Expert Rev Neurother. 2021;21:1-16.

12. Vernillet L, Greene SA, Kamin M. Pharmacokinetics of cenobamate: results from single and multiple oral ascending-dose studies in healthy subjects. Clin Pharmacol Drug Dev. 2020;9:428-443. doi:10.1002/cpdd.769 
13. Cenobamate highlights of prescribing information. Available from: https://www.accessdata.fda.gov/drugsatfda_docs/label/2019/ 212839s000lbl.pdf. Accessed November 16, 2021.

14. Greene S, Orlinski L, Streicher C, Vernillet L. The pharmacokinetics of cenobamate in special populations. Neurology. 2019;92:P1.5-034.

15. Vernillet L, Kamin M. Drug-drug interactions between cenobamate and other antiepileptic drugs: results from phase I studies with carbamazepine, phenobarbital, phenytoin, and divalproex sodium. Clin Pharmacol Ther. 2018;103:S91.

16. Sperling MR, Klein P, Aboumatar S, et al. Cenobamate (YKP3089) as adjunctive treatment for uncontrolled focal seizures in a large, phase 3, multicenter, open-label safety study. Epilepsia. 2020;61:1099-1108. doi:10.1111/epi.16525

17. Zaccara G, Perucca E. Interactions between antiepileptic drugs, and between antiepileptic drugs and other drugs. Epileptic Disord. 2014;16:409-431. doi:10.1684/epd.2014.0714

18. Chung SS, French JA, Kowalski J, et al. Randomized Phase 2 study of adjunctive cenobamate in patients with uncontrolled focal seizures. Neurology. 2020;94:e2311-22. doi:10.1212/WNL.0000000000009530

19. Krauss GL, Klein P, Brandt C, et al. Safety and efficacy of adjunctive cenobamate (YKP3089) in patients with uncontrolled focal seizures: a multicentre, double-blind, randomised, placebo-controlled, dose response trial. Lancet Neurol. 2020;19:38-48. doi:10.1016/S14744422(19)30399-0

20. Lattanzi S, Trinka E, Zaccara G, et al. Adjunctive cenobamate for focal-onset seizures in adults: a systematic review and meta-analysis. CNS Drugs. 2020;34(11):1105-1120. doi:10.1007/s40263-020-00759-9

21. Steinhoff BJ, Ben-Menachem E, Ryvlin P, et al. Efficacy and safety of adjunctive perampanel for the treatment of refractory partial seizures: a pooled analysis of three Phase III studies. Epilepsia. 2013;54 (8):1418-1419. doi:10.1111/epi.12212

22. Ben-Menachem E, Mameniskiene R, Quarato PP, et al. Efficacy and safety of brivaracetam for partial-onset seizures in 3 pooled clinical trials. Neurology. 2016;87(1):314-323. doi:10.1212/WNL.00000000 00002864

23. Mula M, Zaccara G, Galimberti CA, et al. Validated outcome of treatment changes according to International League Against Epilepsy criteria in adults with drug-resistant focal epilepsy. Epilepsia. 2019;60(6):1114-1123. doi:10.1111/epi.14685

24. Chen Z, Brodie MJ, Liew D, Kwan P. Treatment outcomes in patients with newly diagnosed epilepsy treated with established and new antiepileptic drugs: a 30-year longitudinal cohort study. JAMA Neurol. 2018;75(3):279-286. doi:10.1001/jamaneurol.2017.3949

25. Elizebath R, Zhang E, Coe P, Gutierrez EG, Yang J, Krauss GL. Cenobamate treatment of focal-onset seizures: quality of life and outcome during up to eight years of treatment. Epilepsy Behav. 2021;116:107796. doi:10.1016/j.yebeh.2021.107796

26. Strzelczyk A, Mann C, Willems LM, Rosenow F, Bauer S. Cenobamate for the treatment of focal epilepsies. Expert Opin Pharmacother. 2020;21(18):2215-2223. doi:10.1080/14656566.2020.1803830

27. Zaccara G, Franciotta D, Perucca E. Idiosyncratic adverse reactions to antiepileptic drugs. Epilepsia. 2007;48(7):1223-1244. doi:10.1111/ j.1528-1167.2007.01041.x

28. Wilde AAM, Amin AS, Postema PG. Diagnosis, management and therapeutic strategies for congenital long QT syndrome. Heart. 2021; heartjnl-2020-318259. doi:10.1136/heartjnl-2020-318259

29. Dewi IP, Dharmadjati BB. Short QT syndrome: the current evidences of diagnosis and management. J Arrhythm. 2020;36(6):962-966. doi:10.1002/joa3.12439

30. International conference on harmonization of technical requirements for registration of pharmaceuticals for human use. ICH harmonized tripartite guideline. Clinical evaluation of QT/QTc interval prolongation and proarrhythmic potential for non-antiarrhythmic drugs. Available from: https:// www.ich.org/fileadmin/Public_Web_Site/ICH_Products/Guidelines/ Efficacy/E14/E14_Guideline.pdf. Accessed November 16, 2021.
31. Zaccara G, Lattanzi S. Comorbidity between epilepsy and cardiac arrhythmias: implication for treatment. Epilepsy Behav. 2019;97:304-312. doi:10.1016/j.yebeh.2019.05.038

32. Bell GS, Mula M, Sander JW. Suicidality in people taking antiepileptic drugs: what is the evidence? CNS Drugs. 2009;23(4):281-292. doi:10.2165/00023210-200923040-00002

33. Klein P, Devinsky O, French J, et al. Suicidality risk of newer antiseizure medications: a meta-analysis. JAMA Neurol. 2021;78 (9):1118-1127. doi:10.1001/jamaneurol.2021.2480

34. O’Brien TJ, Borghs S, He QJ, Schulz AL, Yates S, Biton V. Longterm safety, efficacy, and quality of life outcomes with adjunctive brivaracetam treatment at individualized doses in patients with epilepsy: an up to 11-year, open-label, follow-up trial. Epilepsia. 2020;61(4):636-646. doi:10.1111/epi.16484

35. Patel AD, Badalamenti V, Gasalla T, Elmoufti S, Elshoff JP. Safety and tolerability of adjunctive brivaracetam in children with focal seizures: interim analysis of pooled data from two open-label trials. Eur J Paediatr Neurol. 2020;25:68-76. doi:10.1016/j.ejpn.2019.11.007

36. Toledo M, Beale R, Evans JS, et al. Long-term retention rates for antiepileptic drugs: a review of long-term extension studies and comparison with brivaracetam. Epilepsy Res. 2017;138:53-61. doi:10.1016/j.eplepsyres.2017.10.008

37. Toledo M, Brandt C, Quarato PP, et al. Long-term safety, efficacy, and quality of life during adjunctive brivaracetam treatment in patients with uncontrolled epilepsy: an open-label follow-up trial. Epilepsy Behav. 2021;118:107897. doi:10.1016/j.yebeh.2021.107897

38. Menzler K, Mross PM, Rosenow F, et al. First clinical postmarketing experiences in the treatment of epilepsies with brivaracetam: a retrospective observational multicentre study. BMJ Open. 2019;9 (11):e030746. doi:10.1136/bmjopen-2019-030746

39. Rheims S, Perucca E, Cucherat M, Ryvlin P. Factors determining response to antiepileptic drugs in randomized controlled trials. A systematic review and meta-analysis. Epilepsia. 2011;52:219-233. doi:10.1111/j.1528-1167.2010.02915.x

40. Zaccara G, Giovannelli F, Cincotta M, Loiacono G, Verrotti A. Adverse events of placebo-treated, drug-resistant, focal epileptic patients in randomized controlled trials: a systematic review. J Neurol. 2015;262:501-515. doi:10.1007/s00415-014-7391-y

41. French JA, Faught E. Rational polytherapy. Epilepsia. 2009;50(Suppl 8):63-68. doi:10.1111/j.1528-1167.2009.02238.x

42. Sake JK, Hebert D, Isojärvi J, et al. A pooled analysis of lacosamide clinical trial data grouped by mechanism of action of concomitant antiepileptic drugs. CNS Drugs. 2010;24(12):1055-1068. doi:10.2165/11587550-000000000-00000

43. Verrotti A, Lattanzi S, Brigo F, Zaccara G. Pharmacodynamic interactions of antiepileptic drugs: from bench to clinical practice. Epilepsy Behav. 2020;104(Pt A):106939. doi:10.1016/j. yebeh.2020.106939

44. Kasteleijn-Nolst Trenite DGA, DiVentura BD, Pollard JR, Krauss GL, Mizne S, French JA. Suppression of the photoparoxysmal response in photosensitive epilepsy with cenobamate (YKP3089). Neurology. 2019;93(6):e559-e567. doi:10.1212/WNL.0000000000007894

45. Keam SJ. Cenobamate: first Approval. Drugs. 2020;80(1):73-78. doi:10.1007/s40265-019-01250-6

46. Patsalos PN, Berry DJ, Bourgeois BF, et al. Antiepileptic drugs-best practice guidelines for therapeutic drug monitoring: a position paper by the subcommission on therapeutic drug monitoring, ILAE commission on therapeutic strategies. Epilepsia. 2008;49(7):1239-1276. doi:10.1111/j.1528-1167.2008.01561.x 


\section{Publish your work in this journal}

Neuropsychiatric Disease and Treatment is an international, peerreviewed journal of clinical therapeutics and pharmacology focusing on concise rapid reporting of clinical or pre-clinical studies on a range of neuropsychiatric and neurological disorders. This journal is indexed on PubMed Central, the 'PsycINFO' database and CAS, and is the official journal of The International Neuropsychiatric Association (INA). The manuscript management system is completely online and includes a very quick and fair peer-review system, which is all easy to use. Visit http://www.dovepress.com/testimonials.php to read real quotes from published authors.

Submit your manuscript here: https://www.dovepress.com/neuropsychiatric-disease-and-treatment-journal 